\title{
Building Moisture Load Analysis Based on Heat and Mass Coupled Transfer
}

\author{
Fanhong Kong1, a
}

\author{
${ }^{1 *}$ School of Energy Science and Engineering, Central South University, Changsha, Hunan, China \\ afhkong1980@163.com
}

Keywords: new-built building; heat and mass coupled transfer; modeled room moisture load; different setting

Abstract. The conventional calculation of building indoor moisture load of always omits the effect of interior moisture release of envelope. However, its effect especially that of new-completely energy-saving building is very large. The paper, which took the new-built building in Harbin as an example, analyzed the effect of heat and mass coupled transfer envelope on modeled room moisture load in cold serious areas. The moisture load modeled results of multilayer envelopes with different setting were contrasted in the first four years use. The result showed that, for a new-built building, the using of vapor retarder on interior of insulation layer or glazed brick on exterior of envelope would increase the moisture load, which would be reduced if defer the time for plastering glazed brick.

\section{Introduction}

In the past, the relative humidity as an important parameter of the building was always omitted. But with the fast development of economy, the inhabitants have a higher demand on the comfort for living environment. Moreover, with the developed high attention on mildew and indoor air quality, the indoor humidity as an important parameter for design attaches more and more importance of designers. The indoor air relative humidity would obviously affect: warm respiratory comfort, the acceptability of indoor air quality, the inhabitant health and the building energy consumption [1]. So the moisture load of the room is a more and more important item for design [2].

The paper investigated the effect of the heat and moisture coupled transfer of new-completely building envelope on its enclosed room moisture load. Taking the building in Harbin, cold serious area of China, as example, the effect of initial moisture content, interior wallpaper, vapor retarder, air layer and exterior glazed brick on moisture release to modeled room was compared and analyzed. The effect of the installation time of the wallpaper and glazed brick was also analyzed.

\section{Mathmatical model}

The complete differential form of conservation laws for moisture and energy can be summarized as follows.

$$
\begin{aligned}
& \frac{\partial\left(\rho_{l} \theta_{l}+\rho_{v}\left(\eta-\theta_{l}\right)\right)}{\partial t}+\frac{\partial}{\partial x}\left(-\rho_{l} \theta_{l} k_{l} \frac{\partial P_{l}}{\partial x}-k_{v} \theta_{v} \frac{\partial p_{v}}{\partial x}\right)=0 \\
& \rho c_{p} \frac{\partial T}{\partial \tau}+h_{v}\left(\frac{\partial}{\partial x}\left(\rho_{l} \theta_{l} k_{l} \frac{\partial P_{l}}{\partial x}\right)-\frac{\partial\left(\rho_{l} \theta_{l}\right)}{\partial t}\right)=\frac{\partial}{\partial x}\left(\lambda_{\text {eff }} \frac{\partial T}{\partial x}\right)
\end{aligned}
$$

Where $\theta$ is the volume moisture percent, and the subscripts $\mathrm{i}, \mathrm{v}$ and 1 denote the ice, vapor, liquid and gas respectively; $\eta$ is the porosity of the porous material; $\lambda_{\text {eff }}$ is the effective heat conduction coefficient; $h_{v}$ is the latent heat of vapor to water phase changing; $k_{v}$ is the vapor infiltration coefficient; and $k_{l}$ is the liquid penetration coefficient.

As for indoor air [3], the mass conservation equations are: 


$$
V \frac{d \theta_{i}}{d t}=A \dot{g}_{w}+n V\left(\theta_{o}-\theta_{i}\right)+\theta_{I M P}+\theta_{\text {vent }}+\theta_{\text {HVAC }}
$$

Where $\theta_{i}$ and $\theta_{o}$ denote indoor and outdoor moisture content respectively; $\dot{g}_{w}$ is the interior moisture release of envelope; $n$ is the ventilation rate; $V$ is the volume of the modeled room; $A$ is the interior surface area of the modeled room; and $\theta_{I M P}, \theta_{\text {vent }}$ and $\theta_{H V A C}$ is the moisture content entered into the modeled room through indoor moisture production, ventilation and HVAC system. According to equation (3), the indoor relative humidity $r h_{i}^{t+\Delta t}$ of the time $t+\Delta t$ can be received. If $r h_{i}^{t+\Delta t}<40 \%$, that is the indoor relative humidity is lower than $40 \%$, then the moisture load of the modeled room is:

$$
\text { MOIST }=V \cdot \frac{\left(\theta_{i}(40 \%)-\theta_{i}\left(r h_{i}^{t+\Delta t}\right)\right)}{\Delta t} .
$$

If $r h_{i}^{t+\Delta t}>60 \%$, that is the indoor relative humidity is higher than $60 \%$, then the moisture load of the modeled room is:

$$
\text { MOIST }=V \cdot \frac{\left(\theta_{i}(60 \%)-\theta_{i}\left(r h_{i}^{t+\Delta t}\right)\right)}{\Delta t} .
$$

If $40 \%<r h_{i}^{t+\Delta t}<60 \%$, that is the indoor relative humidity is higher than $40 \%$, and lower than $60 \%$, then the moisture load of the modeled room is zero.

\section{Simulation properties}

The modeled room is in a new-completely building in Harbin, China that has $12 \mathrm{~m}^{2}$ of living area, $14 \mathrm{~m}^{2}$ of exterior envelope area, which includes $11.3 \mathrm{~m}^{2}$ of opaque wall area and $2.7 \mathrm{~m}^{2}$ of window area as shown in Fig 1. The analyzed envelope, as seen in Fig.1, is typical for cold serious area as Harbin. The wall initial temperature values from assumption that the wall is in thermodynamic equilibrium with ambient air temperature of $295 \mathrm{~K}$. the initial liquid moisture volume percent of slag concrete is $22 \%$, that of EPS board is $2.25 \%$, and $25 \%$ is for cement-lime mortar and cement mortar.

The following building design characteristics and operating conditions have been used during computer modeling: It is supposed that the partition wall and floor is adiabatic and impermeable, only the heat and moisture transfer of the exterior wall and the heat transfer of the out window are taken into account. The indoor moisture generation rate is 0 and ventilation rate is not taken into account. It depended on air-conditioner for heating and cooling.

\section{Results and analysis}

The Fig.3 shows the moisture load of the modeled room changing with the envelope heat and moist transfer. The moisture release of the interior surface with saturated moisture content at initial use was the largest at initial drying due to the convective moisture transfer at surface. So the moisture load of the modeled room was the largest in the first year especially the first few months. This is the reason for the inhabitants feeling of cold and dank for the first year of inhabiting in the new-completely building. With the drying, the moisture release at interior surface was decreased quickly due to the slowly moisture content transfer inner envelope. Several years, 4-6 years depending on the parametric cases, maybe required to dry out the initial moisture in weather condition of Harbin, cold serious area of China[4].

In order to analyze the effect of differential initial moisture content, interior wallpaper, exterior glazed brick and vapor retarder at interior EPS board surface on modeled room moisture load from building initial use. The below conditions on the basis of the above envelope were modeled and compared with the aforeanalyzed result. The first condition about different installation: the air layer of $20 \mathrm{~mm}$ was installed at the exterior face of EPS layer; the polyethylene vapor retarder of $0.1 \mathrm{~mm}$ 
was installed at interior surface of the EPS layer; the ethylene wallpaper was plastered at the interior surface of envelope or the grazed brick of $10 \mathrm{~mm}$ thickness was plastered at the exterior surface of envelope. The second condition about different installing time: the wallpaper was installed a month later or a year later; the grazed brick was plastered a month later or a year later. The third condition about different initial moisture content: the initial moisture content of slag concrete was decreased to $18 \%$ or $15 \%$, or the initial moisture content of EPS layer was decreased to $1.12 \%$.

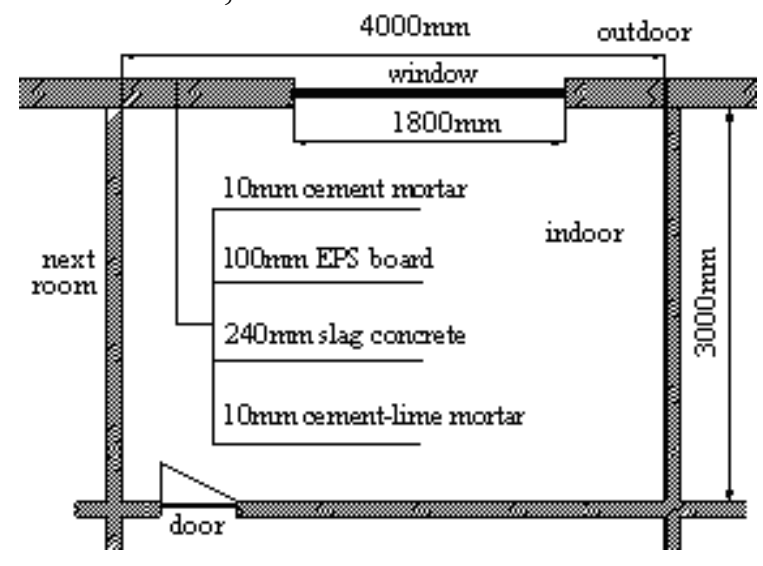

Fig.1 the ichnography of modeled room

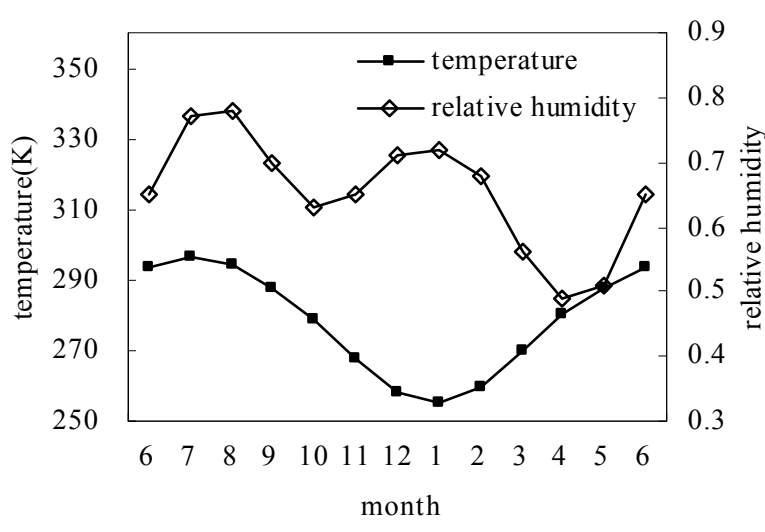

Fig.2 The month average climate condition in Harbin, China

The Fig. 4 shows the moisture load of modeled room with different installation compared with aforeanalyzed result. The exterior surface glazed brick also have obviously effect due to that the large vapor infiltration resistance of the glazed brick decreased the moisture release of the exterior surface which increased the heat transfer coefficient (high moisture content and freezing ice in winter). So the moisture load was lower than compared wall. The time of the glazed brick installation also has effect on the moisture load as seen in Fig.5. The later the installation, the less the effect. The air layer reduced the moisture transfer of the EPS layer to the outside. So the moisture load was lower than that of the compared result in the first two years but higher after the third year due to its lower drying rate[5]. The vapor retarder at the interior face of the EPS layer increased the interior moisture release by reducing the moisture transfer to EPS layer. And the moisture load was a little higher than that of compared result.

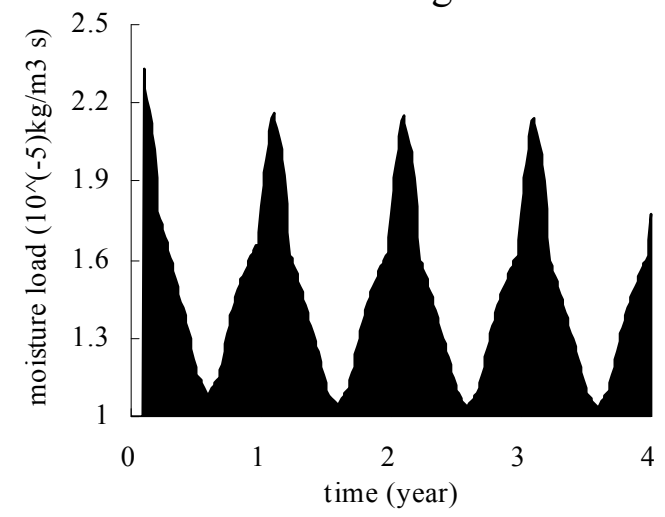

Fig.3 The changing of modeled room moisture load

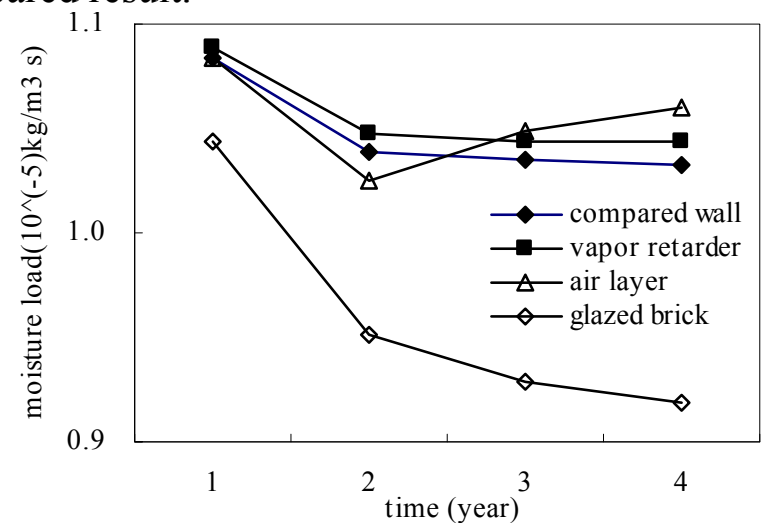

Fig. 4 the comparison of the minimum room moisture load in winter

The less the initial moisture content of the slag concrete, the lower the vapor partial pressure of the envelope interior surface, which leads to the lower moisture content of the modeled room as shown in Fig.6. While the less the initial moisture content of the EPS layer, the better the insulation performance of the envelope. So the vapor partial pressure difference of the interior surface and indoor air would be higher, which increased the moisture load of the modeled room. However, with the drying of the envelope, the discrepancy of the moisture content on the basis of different initial moisture content would be less. 


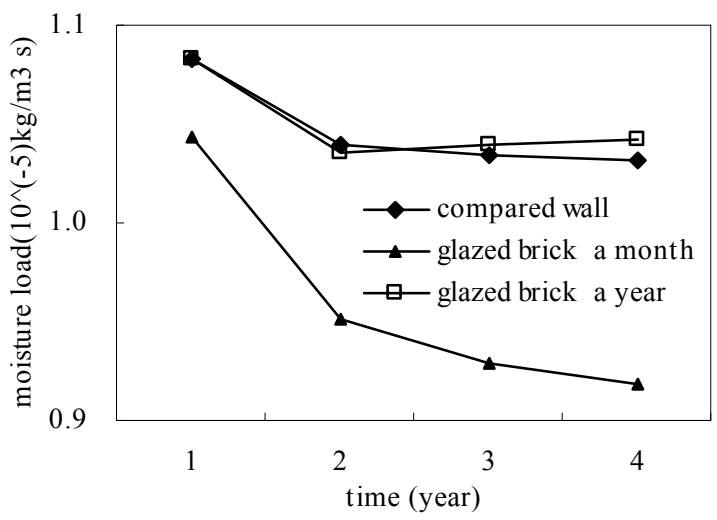

Fig.5 The minimum moisture load of the modeled room in winter

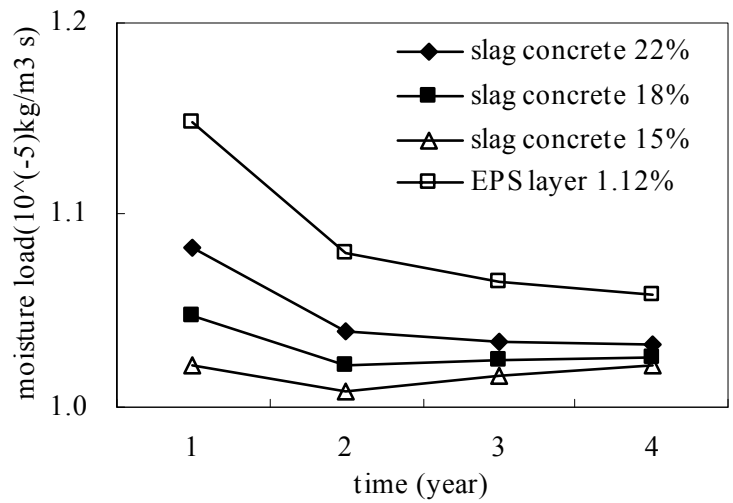

Fig.6 The minimum moisture load of the modeled room in winter

\section{Conclusions}

From above analysis on the moisture load we can see that the installation of the exterior glazed brick would decrease the moisture load, while the air layer and the vapor retarder would increased the moisture content. The effect of initial moisture content of the slag concrete on moisture load is relatively large in winter of the first year and the discrepancy with the compared result would be less with the drying. The installation time of the exterior glazed brick has effect on moisture load, while plaster the wallpaper or not has large effect on moisture load of the modeled room

It should declare that the analysis result is just for the moisture load of the modeled room in a new-completely building, and the conclusions are not suit for the whole building performance.

\section{Acknowledgements}

The project is supported by Postdoctoral Seience Foundation of Central South University and the freedom explore Program of Central South University(2011QNZT098).

\section{References}

[1] W.C.Thomas, D.M.Burch. Experimental Validation of a Mathematical Model for Predicting Water Vapor Sorption at Interior Building Surfaces. ASHRAE Transaction. vol. 96, Feb. 1990, pp. 487-496

[2] Fangting Song, Bin Zhao, Xudong Yang. A New Approach on Zonal Modeling of Indoor Environment with Mechanical Ventilation. Building and Environment. vol. 43, 2008, pp. 278-286

[3] Andreas H. Holm, Hartwig M. Kunzel, Klaus Sedlbauer. Predicting Indoor Temperature and Humidity Conditions Including Hygrothermal Interactions with the Building Envelope. ASHRAE Transaction. vol. 110, Feb. 2004, pp. 820-826

[4] Fanhong Kong, Huaizhu Wang. Building Energy Performance investigation Based on Heat and Mass Coupled Transfer. 2012 Second International Conference on Intelligent System Design and Engineering Application (ISDEA) 87-90

[5] Fanhong Kong, Maoyu Zheng. Effects of Combined Heat and Mass Transfer on Heating Load in Building Drying Period. Energy and Buildings. 2008(40):1614-1622. 